\title{
Intracorporeal Studer Pouch Formation with Balbay's Technique Following Robotic Radical Cystectomy for Bladder Cancer: Experience with 22 Cases with Oncologic and Functional Outcomes
}

\author{
Mevlana Derya Balbay, MD,, Abdullah Erdem Canda, MD, ${ }^{1,2}$ Murat Can Kiremit, MD, and Ersin Koseoglu, MD ${ }^{1}$
}

\begin{abstract}
Aim: Robot-assisted radical cystectomy (RARC) with intracorporeal Studer pouch formation (ICSPF) is increasingly being performed. Balbay's technique of ICSPF replicates the open approach with the additional advantages of inserting internal Double-J stents.

Materials and Methods: Between June 2011 and April 2019, 22 patients with muscle-invasive bladder cancer were included who underwent RARC and ICSPF with Balbay's technique. Mean follow-up was 35.7 months. Operative, postoperative, and pathological measures, complications, and oncologic and functional outcomes were evaluated.

Results: Mean operation time, estimated blood loss, mean lymph node yield, and mean duration of hospital stay were 9.2 hours, $361.4 \mathrm{~mL}, 38.6$, and 10.5 days, respectively. Surgical margins were positive in $3(9.1 \%)$ patients. Postoperative pT stages included pT0 $(n=4)$, pTis $(n=4)$, pT1 $(n=2)$, pT2 $(n=1)$, pT3a $(n=3)$, pT3b $(n=5)$, and pT4a $(n=3)$. Daytime continence outcomes were (patients with $\geq 1$-year follow-up, $n=17)$ as follows: $10(58.8 \%)$ fully continent, $4(23.5 \%)$ mild, and $3(17.7 \%)$ moderate incontinence. Two-year cancerspecific survival, overall survival, and recurrence-free survival were $68.6 \%, 66.0 \%$, and $69.7 \%$, respectively. The retrospective nature of the study was the main limitation. Complications (modified Clavien-Dindo classification, $n=32$ ) included 23 minor and 2 major during the perioperative (0-30 days) period and 3 minor and 4 major during the postoperative (31-90 days) period. Ileus developed in 3 patients $(9.3 \%)$. Readmission rates were $3(13.6 \%)$ and $8(36.4 \%)$ in perioperative and postoperative periods, respectively.

Conclusions: RARC and ICSPF by Balbay's technique have acceptable morbidity, excellent surgical and pathological outcomes, and satisfactory oncologic and functional results with additional advantages of exclusion of external stents, exact replication of the open approach, and fewer gastrointestinal complications.
\end{abstract}

Keywords: bladder cancer, robotic cystectomy, intracorporeal urinary diversion, Studer pouch

\section{Introduction}

$\mathbf{T}$ HE GOLD STANDARD TREATMENT for muscle-invasive and also highest risk, nonmuscle-invasive bladder cancer $(\mathrm{BC})$ is open radical cystectomy $(\mathrm{RC})$ and urinary diversion. ${ }^{1-3}$ Robot-assisted radical cystectomy (RARC) is increasingly being performed in the world. ${ }^{4}$ Although it is a technically difficult and time-consuming procedure to create a robotic intracorporeal pouch following RARC, this approach is increasingly being performed in the world as a minimally invasive surgical approach for more than 15 years..$^{5-8}$

Herein, we present surgical, pathological, and functional outcomes of our modified technique (Balbay's technique) for RARC and intracorporeal Studer pouch formation (ICSPF).

\footnotetext{
${ }^{1}$ Department of Urology, School of Medicine, Koç University, Istanbul, Turkey.

${ }^{2}$ Department of Urology, VKF American Hospital, Istanbul, Turkey.

Video of the surgical procedure was accepted for presentation at the 37th World Congress of Endourology (WCE) that was held from October 29 to November 2, 2019, in Abu Dhabi, UAE. (A video demonstrating this technique is available online.)
} 


\section{Materials and Methods}

Between June 2011 and April 2019, a total of 22 muscleinvasive BC patients who underwent RARC, robot assistedintracorporeal orthotopic urinary diversion, and bilateral extended pelvic lymph node dissection (ePLND) with Balbay's technique were included. Patient demographics and precystectomy pathology are presented in Table 1. Patient demographics, operative and postoperative parameters, pathological outcomes, complications, and functional and oncologic outcomes were evaluated. A video demonstrating this technique is given in Supplementary Video S1.

Two-year overall survival (OS), cancer-specific survival (CSS), and recurrence-free survival rates (RFS) as assessed by local and/or metastatic recurrence with histological or radiologic findings were calculated.

Complications identified during the 0 - to 30 -day period and within 31 to 90 days of surgery were recorded and classified according to the modified Clavien-Dindo system.

\section{Preoperative work-up and preparation}

Radiological evaluations for staging were done by contrast-enhanced thoracoabdominal CT or positron emission tomography-CT.

All patients were hospitalized 1 day before the surgery for a light bowel preparation. Ceftriaxone, $1 \mathrm{~g} \times 2$, and ornida-

Table 1. Demographics of Patients

\begin{tabular}{lc}
\hline Demographics & $\mathrm{n}(\%)$ \\
\hline Number of patients & 22 \\
Gender, male/female ratio & $18 / 4$ \\
Mean patient age $( \pm \mathrm{SD})($ range) (years) & $61.6 \pm 9.4(31-80)$ \\
Mean BMI ( \pm SD) (range) $\left(\mathrm{kg} / \mathrm{m}^{2}\right)$ & $27.5 \pm 1.8(22-35)$ \\
Patients with previous intravesical & $2(9.1)$ \\
BCG therapy & None \\
Patients with previous intravesical & \\
chemotherapy & None \\
Patients with previous bladder & \\
perforation during TURBT & \\
Precystectomy pathology & $5(22.7)$ \\
pT1 & $17(77.3)$ \\
pT2 & \\
ASA score & $5(22.7)$ \\
I & $8(36.4)$ \\
II & $8(36.4)$ \\
III & $1(4.5)$ \\
IV & $2(9.1)$ \\
Previous pelvic radiation history & $1(4.5)$ \\
Neoadjuvant chemotherapy & $19(86.4)$ \\
Smoking history & $3(13.6)$ \\
$\geq 10$ packs/year & $16(72.7)$ \\
None & 0 \\
Median creatinine level ( \pm SD) (range) & $1.15 \pm(0.6-1.94)$ \\
(mg/dL) & \\
$\geq 1.4$ mg/dL & $6(27.3)$ \\
$<1.4$ mg/dL & \\
Presence of additional malignancy & \\
\end{tabular}

ASA $=$ American Society of Anesthesiologists; $\mathrm{BCG}=$ bacillus Calmette-Guérin; $\mathrm{BMI}=$ body mass index; $\mathrm{pT}=$ pathologic; $\mathrm{SD}=$ standard deviation; $\mathrm{TURBT}=$ transurethral resection of bladder tumor. zole, $500 \mathrm{mg} \times 3$, were given intravenously on the day of the surgery as antibiotic prophylaxis.

\section{Surgical technique}

With the patient placed in a $30^{\circ}$ Trendelenburg position, the abdominal cavity is entered using a Veress needle or the open entry method $5 \mathrm{~cm}$ above the umbilicus and insufflated to 12 to $15 \mathrm{~cm} \mathrm{H}_{2} \mathrm{O}$. A total of five trocars are placed (Fig. 1). Two robotic arms are controlled with the left hand. Our RARC and bilateral ePLND techniques were described previously. ${ }^{9-11}$

The limits of ePLND included:

Lateral border: genitofemoral nerve, psoas muscle, and ureters.

Medial border: cut edge of the endopelvic fascia over the neurovascular bundles (NVBs) and internal iliac vessels. Superior border: inferior mesenteric artery, accompanying vena cava.

Inferior border: Cloquet lymph node (LN) and circumflex iliac vein.

For ileal neobladder construction, the patient is placed in nearly supine $\left(<10^{\circ}\right.$ Trendelenburg) position to reduce the gravity and help intestines move freely down to the deepest part of the pelvis.

First, the ileocecal junction is identified using a premeasured tape. The ileum is divided across the zero point, leaving the most distal $20-\mathrm{cm}$ segment of the ileum attached to the cecum. Starting from the zero point (distal cut end of the ileum), using a premeasured tape (Figs. 2 and 3), stay sutures are place at every $10 \mathrm{~cm}$ on each side of the antimesenteric edge until the 40 th $\mathrm{cm}$. Forty and $55 \mathrm{~cm}$ points of the ileal segment are marked with stay sutures placed at the antimesenteric midline. The $10 \mathrm{~cm}$ point of the segment is brought down freely and reaches to the urethral stump without stretching. A $1-\mathrm{cm}$ incision is made on the antimesenteric edge at this point $(10 \mathrm{~cm})$, which is the site for urethral anastomosis. A urethrointestinal anastomosis with a $3 / 0$ absorbable running suture over a Foley catheter is done using a $0^{\circ}$ telescope (Fig. 4). The ileum is divided with the second intestinal stapler at the 55 th $\mathrm{cm}$. Rest of the surgery is completed using a $30^{\circ}$ down telescope.

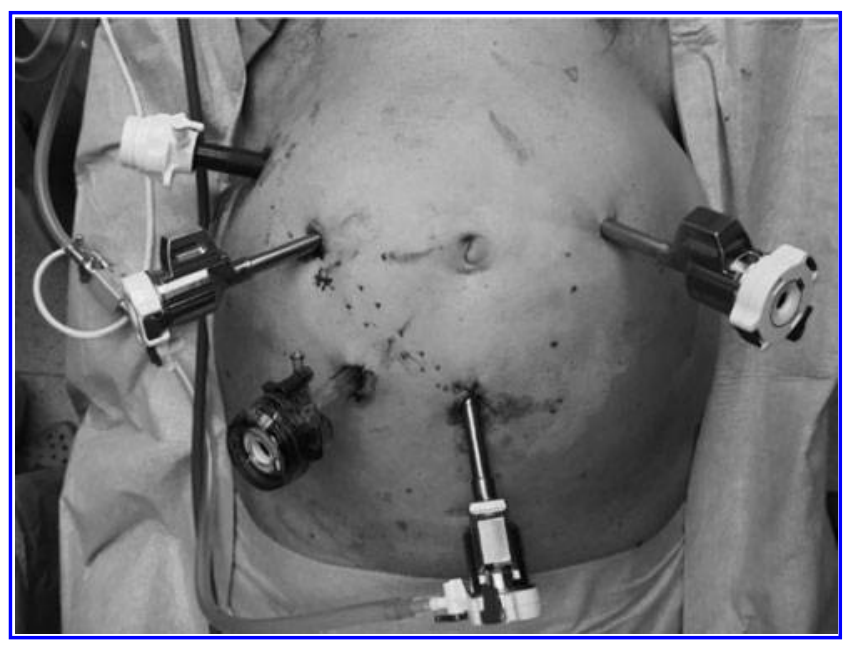

FIG. 1. Port sites. 


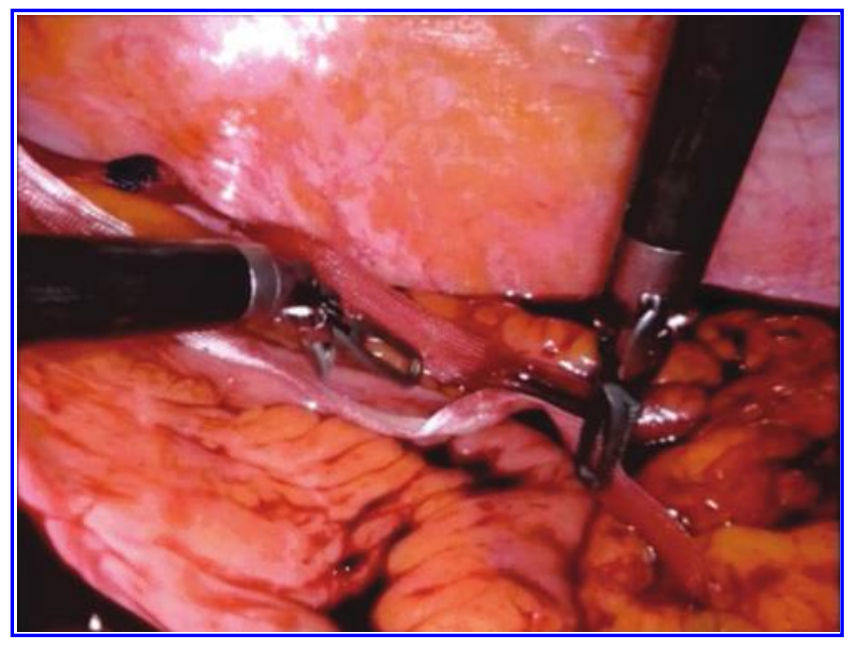

FIG. 2. Measuring the ileal segments to be used with a 20cm-long vascular tape.

An incision is made on the entire antimesenteric border except the most proximal $15 \mathrm{~cm}$, which is going to be the chimney part of the pouch. The intestine is folded on its own at the midpoint of the spared intestinal segment (at the 20th $\mathrm{cm})$. With the help of stay sutures previously placed, the $30 \mathrm{~cm}$ and $10 \mathrm{~cm}$ points as well as 40th and zero points are brought down together and suture tied with $2 / 0$ Vicryl sutures. The posterior plate is formed with continuous suturing using 30-cm-long 3/0 absorbable barbed sutures. Due to previous urethrointestinal anastomosis, the midpoint of the posterior suture line is pulled downward, which therefore assumes the shape of a V. Having completed the posterior plate, a 50-cm-long heavy silk thread $(0 / 0)$ is tied at the tip of the Foley catheter inside, which is then pulled out through the urethra. The Foley catheter is changed with a 50-cm-long $12 \mathrm{~F}$ nasogastric tube (NGT) with the help of the silk thread tied at its tip. The lumen of the NGT easily accommodates two 6F Double-J stents and a guidewire loosely, all of which will be passed through its lumen at the time of ureteroileal anastomosis. Stapler lines at both ends are removed and the NGT is brought out at the level of the open end of the chimney.

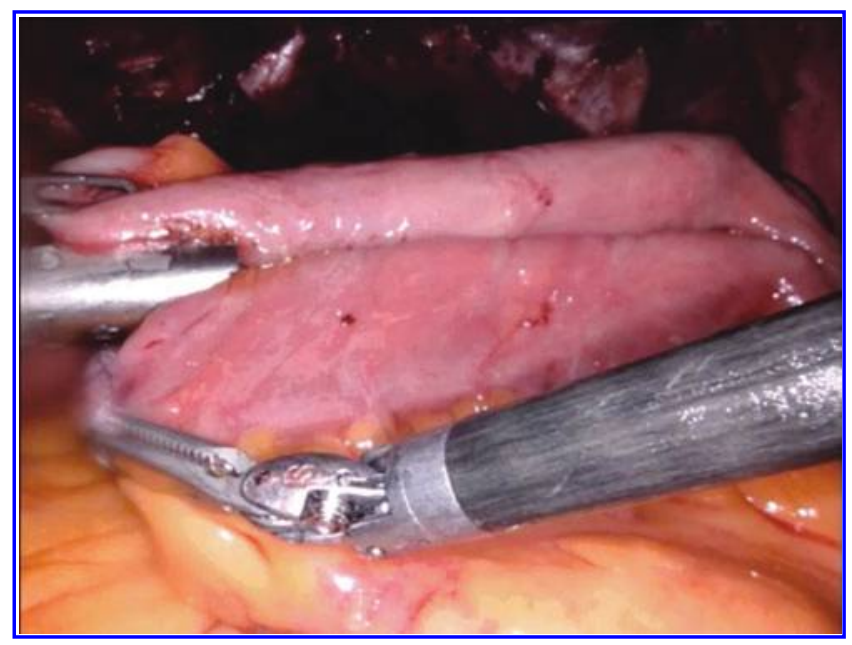

FIG. 3. Side-to-side ileo-ileal anastomosis.

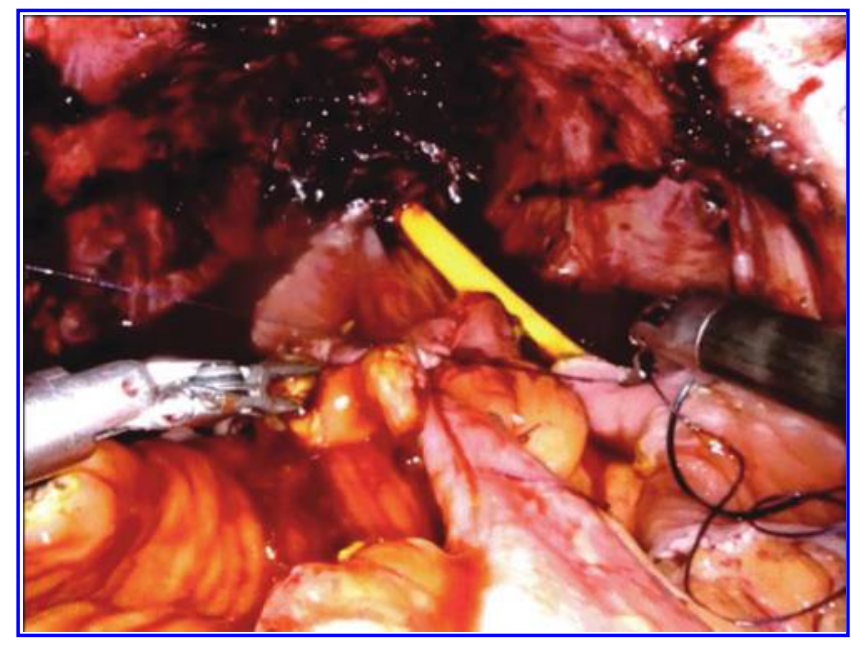

FIG. 4. Urethro-ileal anastomosis.

The anterior suture line of the pouch is completed by bringing the $20 \mathrm{~cm}$ point to $0 / 40 \mathrm{~cm}$ points with a $2 / 0$ Vicryl stay suture. Corresponding edges of the intestinal segment are closed by running 3/0 absorbable barbed sutures. When completed, a vertical, anterior suture line will be formed with the afferent loop shifted toward the right.

Both ends of the distal ureters are trimmed and spatulated to form a Wallace-type ureteroureteric anastomosis as medial spatulated edges of both ureters are sutured together with a running 3/0 absorbable barbed suture. The lateral spatulated edge of the left ureter is anastomosed to the posterior wall of the proximal chimney opening with a similar suture. Halfway through the ureteral-ileal anastomosis, two 6F Double-J stents and a guidewire were inserted from the urethral end of the NGT, one by one, all of which exit out at the level of the ureteral-ileal anastomosis site (Fig. 5). A robotic grasper holds and directs Double-J stents into both ureters up to the renal pelvis. The NGT is withdrawn as the free end of the guidewire is grasped. Over this guidewire, a Foley catheter is inserted through the external urethral meatus into the neobladder lumen. Its balloon is inflated in the pouch and the remaining anterior opening between the common ureteral

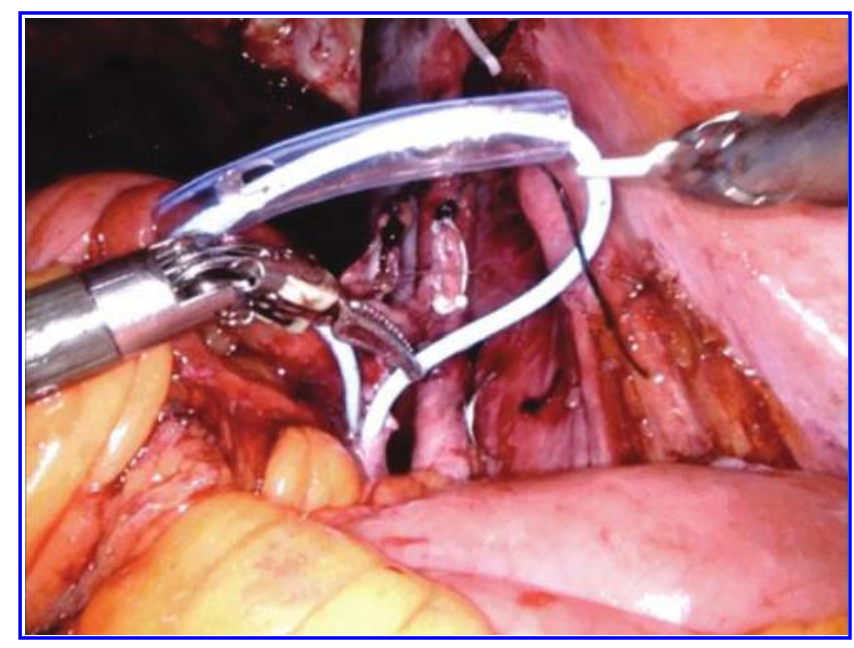

FIG. 5. Internal Double-J stenting. 


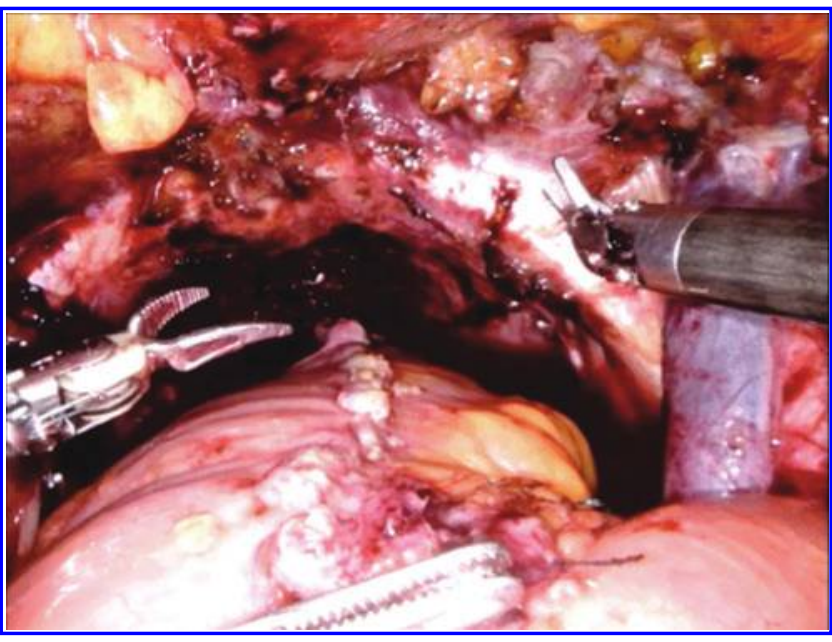

FIG. 6. Distended Studer pouch.

duct and anterior wall of the proximal chimney opening is closed with the same suture. When all suture lines are closed, the intestinal neobladder is filled with $150 \mathrm{~mL}$ of saline (Fig. 6). Should any leakage be noted, additional sutures are placed to achieve a watertight anastomosis.

\section{Postoperative management}

We applied the enhanced recovery after surgery protocol for the patients included in our series, which included early mobilization on postoperative day 1, withdrawal of the NGT on day 1 , and starting of oral feeding at postoperative 24 hours, comprising $10 \mathrm{~mL}$ of water and $10 \mathrm{~mL}$ of a complete balanced nutrition drink enriched with protein and calories (Ensure ${ }^{\circledR}$, Abbott) every 1 hour, which is increased to $20 \mathrm{~mL}$ of water and $20 \mathrm{~mL}$ of a complete balanced nutrition drink enriched with protein and calories (Ensure, Abbott) every 1 hour on day 2 if tolerated well and if no nausea and vomiting occur. Thereafter, oral feeding is proceeded with soft and regular diets as tolerated.

Table 2. Operative and Postoperative Parameters

\begin{tabular}{|c|c|}
\hline Parameters and complications & $\mathrm{n}(\%)$ \\
\hline \multicolumn{2}{|l|}{ Surgery type } \\
\hline a. Bilateral NVB sparing & $21(95.5)$ \\
\hline b. Unilateral NVB sparing & $1(4.5)$ \\
\hline $\begin{array}{l}\text { c. Bilateral extended LN } \\
\text { dissection }\end{array}$ & $22(100)$ \\
\hline $\begin{array}{l}\text { Mean operative time }( \pm \mathrm{SD}) \\
\text { (range) (hours) }\end{array}$ & $9.2 \pm 1.7(6.5-11.5)$ \\
\hline Mean EBL $( \pm \mathrm{SD})$ (range) $(\mathrm{mL})$ & $361.4 \pm 208.5(100-800)$ \\
\hline $\begin{array}{l}\text { Mean time to liquid diet }( \pm S D) \\
\text { (range) (days) }\end{array}$ & $2.5 \pm 1.22(1-8)$ \\
\hline $\begin{array}{l}\text { Mean time to regular diet }( \pm \mathrm{SD}) \\
\text { (range) (days) }\end{array}$ & $5.1(3-11)$ \\
\hline $\begin{array}{l}\text { Mean time to ambulation }( \pm \mathrm{SD}) \\
\quad \text { (range) (days) }\end{array}$ & $2.4 \pm 0.88(1-5)$ \\
\hline $\begin{array}{l}\text { Mean lodge drain removal time } \\
( \pm \mathrm{SD}) \text { (range) (days) }\end{array}$ & $8 \pm 4.4(3-30)$ \\
\hline $\begin{array}{l}\text { Median length of hospital stay } \\
( \pm \text { SD) (range) (days) }\end{array}$ & $10.5 \pm 6.8(5-30)$ \\
\hline
\end{tabular}

$\mathrm{EBL}=$ estimated blood loss; $\mathrm{LN}=$ lymph node $\mathrm{NVB}=$ neurovascular bundle.
Table 3. Postoperative Pathological Outcomes

\begin{tabular}{lc}
\hline$p T$ stage & $\mathrm{n}(\%)$ \\
\hline Organ-confined disease & $11(50)$ \\
pT0 & $4(18.2)$ \\
Primary CIS & $4(18.2)$ \\
pT1 & $2(9.1)$ \\
pT2 & $1(4.5)$ \\
Local extravesical disease & $11(50)$ \\
pT3a & $3(13.6)$ \\
pT3b & $5(22.8)$ \\
pT4a & $3(13.6)$ \\
Staging and LN yield & \\
pN0 & $14(63.7)$ \\
pN1 & $1(4.5)$ \\
pN2 & $6(27.3)$ \\
pN3 & $1(4.5)$ \\
Mean LN yield ( \pm SD) & $38.6 \pm 11.5$ \\
LN yield range & $24-60$ \\
LN involvement stratified by pT stage & $n=8$ \\
pT1 or less & 0 \\
pT2 & 0 \\
pT3 & $5(62.5)$ \\
pT4 & $3(100)$ \\
Positive soft tissue surgical margins (PSM) & $3(13.6)$ \\
Incidental prostate adenocarcinoma & $5(27.8)$ \\
Gleason score 3+3 & $3(16.7)$ \\
Gleason score $3+4$ & $2(11.1)$ \\
\hline
\end{tabular}

CIS $=$ carcinoma in situ.

\section{Functional evaluation}

Daytime urinary incontinence (UI) was measured as described by Lantz et al., ${ }^{12}$ whereas nighttime UI was measured as described by Kulkarni et al. ${ }^{13}$

Daytime UI: None (0-1 security pad/day), mild (1-2 pads/day), moderate ( 3 pads/day), and severe ( $>3$ pads/day). Nighttime UI: Good (dry with no protection), fair (dry with one awakening), and poor (wet, leakage, and UI during sleep).

Erectile function was assessed by using the International Index of Erectile Function (IIEF) scores described by Rosen et al. ${ }^{14}$

IIEF scoring: Severe erectile dysfunction (ED) (IIEF scores $<7$ ), moderate ED (IIEF scores 7-12), mild-moderate ED (IIEF scores 13-18), mild ED (IIEF scores 19-24), and no ED (IIEF scores $>25$ )

All patients with preoperative erectile function were suggested to use oral phosphodiesterase type 5 (PDE-5) inhibitors after the urethral catheter is removed.

\section{Statistical analysis}

Data are descriptively reported using mean, median, and range. The 2-year OS, CSS, and RFS were assessed using the Kaplan-Meier estimator.

\section{Results}

Data are prospectively collected and recorded. Overall, there were 18 male and 4 female patients. Mean operative 
Table 4. Complications of Patients FROM 0 TO 30 DAYS AND FROM 31 TO 90 DAYS

\begin{tabular}{|c|c|c|}
\hline & $\begin{array}{c}\text { 0-30 Days } \\
\text { (perioperative), } \\
\mathrm{n}\end{array}$ & $\begin{array}{c}\text { 31-90 Days } \\
\text { (postoperative), } \\
\mathrm{n}\end{array}$ \\
\hline \multicolumn{3}{|l|}{ I. Gastro-urinary } \\
\hline $\begin{array}{l}\text { 1. Prolonged } \\
\text { lymphatic drainage } \\
\text { from the drain }\end{array}$ & 3 (Clavien 2) & 0 \\
\hline $\begin{array}{l}\text { 2. Ureteral } \\
\text { anastomosis } \\
\text { stricture }\end{array}$ & 0 & 2 (Clavien 3a) \\
\hline 3. Acute hepatitis ${ }^{a}$ & 1 (Clavien 2) & 0 \\
\hline 4. Nausea & 1 (Clavien 1) & 1 (Clavien 1) \\
\hline 5. Vomiting & 1 (Clavien 1) & 0 \\
\hline \multicolumn{3}{|l|}{ II. Infectious diseases } \\
\hline $\begin{array}{l}\text { 1. Urinary tract } \\
\text { infection }\end{array}$ & 6 (Clavien 2) & 2 (Clavien 2) \\
\hline $\begin{array}{l}\text { 2. Surgical site } \\
\text { infection }\end{array}$ & 1 (Clavien 2) & 0 \\
\hline 3. Septicemia & 1 (Clavien 4b) & 0 \\
\hline \multicolumn{3}{|l|}{ III. Gastrointestinal } \\
\hline Ileus & 2 (Clavien 2) & 1 (Clavien 3b) \\
\hline \multicolumn{3}{|l|}{ IV. Cardiac } \\
\hline $\begin{array}{l}\text { Acute myocardial } \\
\text { infarction }^{\mathrm{b}}\end{array}$ & 1 (Clavien 4a) & 0 \\
\hline \multicolumn{3}{|l|}{ V. Bleeding } \\
\hline Transfusion & 3 (Clavien 2) & 0 \\
\hline \multicolumn{3}{|l|}{ VI. Thromboembolic } \\
\hline $\begin{array}{c}\text { Deep venous } \\
\text { thrombosis }\end{array}$ & 1 (Clavien 2) & 0 \\
\hline VII. Uremia & 2 (Clavien 2) & 1 (Clavien 4a) \\
\hline \multicolumn{3}{|l|}{ VIII. Pulmonary } \\
\hline Atelect & 2 (Clavien 1) & 0 \\
\hline
\end{tabular}

Grade of complication

according

to the modified

Clavien system

Overall: $\mathrm{n}=25 \quad$ Overall: $\mathrm{n}=7$

\begin{tabular}{lrl}
\hline 1 & 4 & 1 \\
2 & 19 & 2 \\
$3 \mathrm{a}$ & 0 & 2 \\
$3 \mathrm{~b}$ & 0 & 1 \\
$4 \mathrm{a}$ & 1 & 1 \\
$4 \mathrm{~b}$ & 1 & 0 \\
5 & 0 & 0 \\
$\begin{array}{c}\text { Minor complication } \\
\quad \text { Grades 1 and 2) }\end{array}$ & 23 & 3 \\
$\begin{array}{c}\text { Major complication } \\
\text { (Grade 3-5) }\end{array}$ & 2 & 4 \\
$\begin{array}{l}\text { Readmission rate } \\
\text { due to minor }\end{array}$ & 3 & 5 \\
complications & & \\
$\begin{array}{l}\text { Readmission rate } \\
\text { due to major } \\
\text { complications }\end{array}$ & 0 & 3 \\
\hline
\end{tabular}

\footnotetext{
${ }^{\text {a }}$ This patient developed hepatitis with elevated liver enzymes during perioperative follow-up, which resolved with conservative measures. During follow-up, metastatic lesions in the liver were identified and the patient died in the postoperative 7 th month.

${ }^{\mathrm{b}}$ Following acute myocardial infarction during the perioperative period, this patient developed ischemic brain injury and renal failure with prolonged lymphatic drainage and died $>90$ days after surgery.
}

time was 9.2 hours and mean estimated blood loss (EBL) was $361.4 \mathrm{~mL}$. Mean duration of hospital stay was 10.5 days. Operative, postoperative, and pathological parameters and complications are shown in Tables 2 to 4 . Functional outcomes, including urinary daytime and nighttime continence and erectile function, are presented in Tables 5 and 6.

Incidental prostate cancer was identified in $5(27.8 \%)$ patients. Positive surgical margin (SM) was identified in 3 (9.1\%) patients. Mean LN yield was 38.6. Two patients received neoadjuvant chemotherapy and four patients received adjuvant chemotherapy. Mean follow-up was 35.7 months.

Patients developed 23 minor and 2 major complications during the perioperative (0-30 days) period and 3 minor and 4 major complications during the postoperative (31-90 days) period. One patient had acute myocardial infarction and developed hypoxic brain injury and kidney failure and then died $>90$ days after surgery. One patient developed septicemia and was treated with antibiotics in the intensive care unit. Three patients developed ileus and required readmission. Two were treated with conservative measures and with NGT insertion. One required surgical exploration with no abnormal findings and ileus resolved spontaneously. Three patients required transfusion ( $1 \mathrm{U}$ of red blood cells) due to a slight decrease in hematocrit levels.

Two patients had stricture formation at the ureteroileal anastomosis site. One of them developed postrenal kidney failure and required readmission and bilateral percutaneous nephrostomy (PCN) insertion. During follow-up, bilateral PCN tubes were removed consecutively, and this patient has a slightly elevated serum creatinine level and does not require any dialysis. This patient is being followed up for chronic kidney disease without PCN tubes. The second patient also required bilateral PCN insertion and was lost to follow-up. One patient developed acute hepatitis, which resolved spontaneously with conservative treatment. This patient developed liver metastases and died of it in 7 months. Readmission rates were $3(13.6 \%$ ) (minor) and $8(36.4 \%)$ (5 minor and 3 major) in perioperative and postoperative periods, respectively (Table 4).

For patients with $\geq 1$-year follow-up $(n=17)$, daytime continence outcomes were as follows: $10(58.8 \%)$ fully continent, $4(23.5 \%)$ mild, and $3(17.7 \%)$ moderate incontinence. None had severe incontinence (Table 5). Erectile function outcomes are presented in Table 6 .

Two-year CSS, OS, and RFS were $68.6 \%, 66.0 \%$, and $69.7 \%$, respectively.

During follow-up, seven patients died. Of those, one was due to myocardial infarction and subsequent complications at 120 days after surgery. Six patients died due to disease progression and metastasis.

\section{Discussion}

We have been performing RARC with intracorporeal urinary diversion (ICUD) almost for a decade. Before applying the current technique, we have had experience on and performed considerable numbers of open/RARC with intracorporeal Studer pouch/ileal conduit procedures in addition to $>500$ robotassisted radical prostatectomy (RARP) cases. Therefore, the current series includes procedures beyond the learning curve of the surgeons as the authors previously published their initial technique of RARC and ICUD outcomes elsewhere. ${ }^{9-11}$ 
Table 5. Postoperative Urinary Continence Outcomes of Male and Female Patients Who Have Completed Postoperative $\geq 1$-Year Follow-Up $(N=17)$

\begin{tabular}{|c|c|c|c|c|c|c|c|c|c|}
\hline \multirow[b]{2}{*}{$M / F$} & \multirow{2}{*}{$\begin{array}{l}\text { Follow-up } \\
\text { (months) }\end{array}$} & \multirow{2}{*}{$\begin{array}{l}\text { NVB sparing, } \\
\mathrm{n}(\%)\end{array}$} & \multicolumn{4}{|c|}{$\begin{array}{l}\text { Postoperative daytime incontinence, } \\
\mathrm{n}(\%)\end{array}$} & \multicolumn{3}{|c|}{$\begin{array}{l}\text { Postoperative nighttime } \\
\text { incontinence, } \mathrm{n}(\%)\end{array}$} \\
\hline & & & None & Mild & Moderate & Severe & Good & Fair & Poor \\
\hline $\begin{array}{l}\text { Male } \\
\qquad(n=13)\end{array}$ & $47.3 \pm 32.4(12-94)$ & $\begin{array}{l}\text { Bilateral: } 12 \text { (92.3) } \\
\text { Unilateral: } 1 \text { (7.7) }\end{array}$ & $10(76.9)$ & $2(15.4)$ & $1(7.7)$ & N/A & $7(53.8)$ & $2(15.4)$ & $4(30.8)$ \\
\hline $\begin{array}{l}\text { Female } \\
\qquad(n=4)\end{array}$ & $35.3 \pm 42.8(13-58)$ & Bilateral: 4 (100) & - & $2(50)$ & $2(50)$ & N/A & $1(25)$ & $3(75)$ & - \\
\hline $\begin{array}{l}\text { Total M/F } \\
\qquad(n=13 / 4)\end{array}$ & $44.5 \pm 30.4(12-94)$ & $\begin{array}{l}\text { Bilateral: } 16 \text { (94.1) } \\
\text { Unilateral: } 1 \text { (5.9) }\end{array}$ & $10(58.8)$ & $4(23.5)$ & $3(17.7)$ & N/A & $8(47.1)$ & $5(29.4)$ & $4(23.5)$ \\
\hline
\end{tabular}

$\mathrm{F}=$ female; $\mathrm{M}=$ male; $\mathrm{N} / \mathrm{A}=$ not applicable.

In Balbay's technique of constructing ICSPF, a vascular tape $20 \mathrm{~cm}$ in length is used for exact measurements of a $55-\mathrm{cm}$ ileal segment to construct the pouch, and holding on stay sutures (3/0 Vicryl) are placed on both sides at 10,20, 30,40 , and $55 \mathrm{~cm}$ points of the segregated ileal segment, which allows less traumatic manipulation of the ileum. Joining corresponding points on the ileum assures double folding of the pouch, which has been a major criticism of robotic intracorporeal pouch construction so far. Thus, Balbay's technique replicates the open approach, including double folding, and results in sufficient pouch volume with minimal pressure for urine storage. Studer's open technique requires double folding of ileal segments with internal stenting. ${ }^{15}$ Patients leave the operating room with a drain and a urethral catheter only. There are no ureteral catheters for bridging between the abdominal wall and neobladder, which prevent intestinal looping around these. This might also reduce both the number and severity of intestinal complications compared with previously published series.

In the International Robotic Cystectomy Consortium (IRCC) study comparing ICUD $v s$ extracorporeal urinary diversion following RARC, 90-day complication rates were $41 \%$ vs $49 \%$, favoring the ICUD group. ${ }^{7}$ Patients in the ICUD group had $32 \%$ of gastrointestinal complications. ${ }^{7}$ In our series, of the 32 complications, we observed ileus in $3(9.3 \%)$ patients during the 90-day period. Therefore, one of the important advantages of our technique might be the decreased gastrointestinal complications. Internal stenting directs patient's own sterile urine into the pouch, which provides continuous low-pressure irrigation and helps washing out mucus formed by the ileal segments. In the postoperative follow-up, drain creatinine levels proved that drain fluid was mainly lymphatic. Double-J stents are easily removed with a flexible ureteroscope. Leaving Double-J stents longer assures ureteral drainage and obviates the need for possible intervention in ureteral-intestinal anastomosis problems.

A positive $\mathrm{SM}$ rate $(<10 \%)$ and $\mathrm{LN}$ yield $(>15)$ are accepted as the most important factors related to surgical oncologic quality in open RC for $\mathrm{BC} .{ }^{15,16}$ The largest multicenter RARC studies, including the EAU Robotic Urology Section and IRCC series, reported $4.8 \%$ and $7 \%$ positive SM rates, respectively. ${ }^{8,17}$ In our series, SMs were positive in $3(9.1 \%)$ patients and mean LN yield was 38.6. Patients with positive SMs had pT4a $(n=2)$ and pT3a $(n=1)$ disease. Positive LNs were detected in $8(36.4 \%)$ patients, all with $\geq \mathrm{pT} 3$ disease. These results are suggestive of proper oncological safety of our technique.

In our series, we observed 25 and 7 complications during perioperative and postoperative periods, respectively (Table 4). Of those 32 complications, most were $(n=26$, $81.0 \%$ ) minor complications (Grades 1 and 2). One of the patients had acute myocardial infarction during the perioperative period, this patient thereafter developed multiple complications mostly due to acute myocardial infarction, including ischemic brain injury and renal failure with prolonged lymphatic drainage, and died $>90$ days after surgery. If this patient is excluded, the number of complications would be even lower in our series. During the perioperative period, prolonged lymphatic drainage $(n=3,12 \%)$ and urinary tract infection $(n=6,24 \%)$ were the most common complications. This might be reflecting our previous experience on robotic surgery. In our previous series of 98 cases with RARC and ICSPF, we observed 30 minor and 20 major complications in the perioperative period and 6 minor and 7 major complications in the postoperative period. ${ }^{9}$

Table 6. Postoperative Erectile Function Outcomes of Patients with Mild or No Preoperative Erectile Dysfunction Who Have Completed Postoperative $\geq 1$-Year Follow-Up $(N=17)$

\begin{tabular}{lcccc}
\hline $\begin{array}{l}\text { Preoperative erectile function } \\
\text { status according to IIEF score }\end{array}$ & $\begin{array}{c}\text { Mean preoperative } \\
\text { IIEF score }\end{array}$ & $\begin{array}{c}\text { NVB sparing, } \\
\mathrm{n}(\%)\end{array}$ & $\begin{array}{c}\text { Postoperative } \\
\text { PDE-5-I use, } \\
\mathrm{n}(\%)\end{array}$ & $\begin{array}{c}\text { Mean IIEF } \\
\text { score at latest FU }\end{array}$ \\
\hline $\begin{array}{l}\text { Mild dysfunction } \\
\quad \text { IIEF score of 19-24) }(n=4)\end{array}$ & $21.5 \pm 1.09(19-24)$ & Bilateral: $4(100)$ & $4(100)$ & $13.5 \pm 4.6(10-16)$ \\
No dysfunction (IIEF score $>24)(n=10)$ & $50.6 \pm 10.4(38-67)$ & $\begin{array}{l}\text { Bilateral: } 9(90) \\
\text { Unilateral: } 1(10)\end{array}$ & $6(60)$ & $32.4 \pm 7.4(9-45)$
\end{tabular}

$\mathrm{FU}=$ follow-up; IIEF = International Index of Erectile Function; PDE-5-I=phosphodiesterase type 5 inhibitor. 
Table 7. Outcomes of Intracorporeal Neobladder

\begin{tabular}{|c|c|c|c|c|c|c|c|c|}
\hline Year & Author & Ref. & $\mathrm{n}$ & $\begin{array}{c}\text { Operation } \\
\text { time (minutes) }\end{array}$ & $E B L(m L)$ & $\begin{array}{l}\text { Transfusion } \\
\text { rate }(\%)\end{array}$ & $\begin{array}{c}\text { Conversion } \\
\text { rate }\end{array}$ & $\begin{array}{c}\operatorname{LOS} \\
\text { (days) }\end{array}$ \\
\hline 2019 & Current series & - & 22 & 552 & 361.4 & 13.6 & 0 & 10.5 \\
\hline 2015 & $\begin{array}{l}\text { Schwentner } \\
\text { et al. }\end{array}$ & 21 & 62 & 477 & 385 & NR & 0 & 16.7 \\
\hline 2015 & Atmaca et al. & 23 & 32 & 586 & 412.5 & 56 & $\mathrm{NR}$ & 17.4 \\
\hline 2014 & Collins et al & 18 & 80 & 420 & 475 & NR & 5.7 & 9 \\
\hline 2014 & Desai et al. & 22 & 132 & 456 & 430 & NR & NR & 11 \\
\hline 2014 & Desai et al. & 24 & 18 & 387 & 200 & 17 & 0 & 9 \\
\hline 2012 & Goh et al. & 25 & 8 & 450 & 225 & 38 & 0 & 8 \\
\hline 2012 & Canda et al. & 11 & 25 & 594 & 429.5 & NR & 0 & 10.5 \\
\hline
\end{tabular}

LOS = length of hospital stay; NR = not reported.

Collins et al. published minor and major complication rates as $17 \%$ and $27 \%$, respectively, in the early postoperative period and $11 \%$ and $19 \%$, respectively, in the late postoperative period at the Karolinska Institute, including 80 patients with RARC and intracorporeal neobladder. ${ }^{18}$ Recently, Simone et al. reported a $42.2 \%$ complication rate in 64 patients who underwent RARC and intracorporeal neobladder. ${ }^{19}$ Minervini et al. reported their outcomes of 18 patients who underwent RARC with intracorporeal neobladder formation. $^{20}$ Postoperative surgical complications occurred in 4 (22.1\%) patients (Clavien-Dindo Grade 3, $n=1$, and Grade 1 , $n=3$ ) and postoperative, medical, Clavien-Dindo Grade 2 complications occurred in $3(16.7 \%)$ patients. ${ }^{20}$ Regarding the series of RARC and ICSPF, including 62 patients, Schwentner et al. reported the early ( $<30$ days) complication rates as $24.2 \%$ and $25.8 \%$ for minor (Grades 1 and 2) and major (Grades 3-5) complications, respectively. ${ }^{21}$

In our series, 17 patients had $\geq 1$-year follow-up and of those, 16 and 1 had bilateral and unilateral NVB sparing, respectively. Daytime and nighttime continence outcomes seem to be better in males $(n=13) ; 77 \%$ had no daytime incontinence and $54 \%$ had good nighttime continence (Table 4). These promising outcomes, particularly in male patients, might be due to preserving both bilateral NVBs in most patients (92\%) and also a long urethral length. In a small group of females $(n=4), 50 \%$ had mild and $50 \%$ moderate daytime incontinence and $25 \%$ good and $75 \%$ fair nighttime continence. None of our patients developed severe daytime incontinence in both groups. In our study, full continence was defined as 0 to 1 security pad/day and mild incontinence was defined as 1 to 2 pads/day. ${ }^{12,13}$ Desai et al. described continence as 0 to $1 \mathrm{pad} /$ day and 2 or more pads were accepted as incontinence and they reported 1-year daytime continence rates ( $0-1 \mathrm{pad} /$ day $)$ as $90 \%$ in their series of RARC and intracorporeal neobladder that included data available for 73 patients who had completed at least 6 months of follow-up. ${ }^{22}$ If we had similarly included patients using 1 $\mathrm{pad} /$ day into the continent group, our continence rate would exceed $90 \%$.

We have evaluated erectile functional outcomes on 10 patients with $\geq 1$-year follow-up $(n=14)$ and no preoperative ED. Bilateral NVB sparing $(n=9)$ and unilateral NVB sparing $(n=1)$ were performed in this patient group and only six patients used PDE-5 inhibitors following removal of the urethral catheter (Table 5). Of those 10 patients, 7 (\%70) had no postoperative ED, suggesting promising erectile function outcomes. Table 7 presents outcomes of selected published series on intracorporeal neobladder formation following RARC for BC. Operation time, EBL, transfusion rates, conversion rates, and length of hospital stay seem to be similar in most series.

Main limitations of the present study are it being retrospective in nature, including limited numbers of patients, absence of long-term follow-up time, and not having comparative outcomes.

\section{Conclusions}

The preliminary outcomes of our series of RARC and ICSPF with Balbay's technique with exact measurement and double folding of the ileal segment, ureteral-ileal anastomosis at the $10 \mathrm{~cm}$ point, and internal stenting suggest safe, feasible, and reliable operative, postoperative, pathological, oncological, and functional outcomes with lower gastrointestinal complication rates.

\section{Author Disclosure Statement}

No competing financial interests exist.

\section{Funding Information}

No funding was received for this article.

\section{Supplementary Material}

Supplementary Video S1

\section{References}

1. Siegel RL, Miller KD, Jemal A. Cancer statistics, 2018. CA Cancer J Clin 2018;68:7-30.

2. Huang GJ, Stein JP. Open radical cystectomy with lymphadenectomy remains the treatment of choice for invasive bladder cancer. Curr Opin Urol 2007;17:369-375.

3. Chopra S, Metcalfe C, de Castro Abreu AL, et al. Port placement and docking for robotic surgery: The University of Southern California Approach. J Endourol 2015;29:868-872.

4. Gill I, Cacciamani G. LBA3 the changing face of urologic oncologic surgery from 2000-2018 (63 141 patients) impact of robotics. J Urol 2018;199:e577-e578.

5. Beecken WD, Wolfram M, Engl T, et al. Robotic-assisted laparoscopic radical cystectomy and intra-abdominal formation of an orthotopic ileal neobladder. Eur Urol 2003;44: 337-339. 
6. Thress TM, Cookson MS, Patel S. Robotic cystectomy with intracorporeal urinary diversion: Review of current techniques and outcomes. Urol Clin North Am 2018;45:67-77.

7. Ahmed K, Khan SA, Hayn MH, et al. Analysis of intracorporeal compared with extracorporeal urinary diversion after robot-assisted radical cystectomy: Results from the International Robotic Cystectomy Consortium. Eur Urol 2014;65:340-347.

8. Hussein AA, May PR, Jing Z, et al. Outcomes of intracorporeal urinary diversion after robot-assisted radical cystectomy: Results from the International Robotic Cystectomy Consortium. J Urol 2018;199:1302-1311.

9. Gok B, Atmaca AF, Canda AE, et al. Robotic radical cystectomy with intracorporeal studer pouch formation for bladder cancer: Experience in ninety-eight cases. J Endourol 2019;33:375-382.

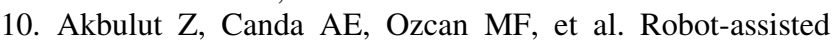
laparoscopic nerve-sparing radical cystoprostatectomy with bilateral extended lymph node dissection and intracorporeal studer pouch construction: Outcomes of first 12 cases. J Endourol 2011;25:1469-1479.

11. Canda AE, Atmaca AF, Altinova S, et al. Robot-assisted nerve-sparing radical cystectomy with bilateral extended pelvic lymph node dissection (PLND) and intracorporeal urinary diversion for bladder cancer: Initial experience in 27 cases. BJU Int 2012;110:434-444.

12. Lantz AG, Saltel ME, Cagiannos I. Renal and functional outcomes following cystectomy and neobladderreconstruction. Can Urol Assoc J 2010;4:328-331.

13. Kulkarni JN, Pramesh CS, Rathi S, Pantvaidya GH. Longterm results of orthotopic neobladder reconstruction after radical cystectomy. BJU Int 2003;91:485-488.

14. Rosen RC, Riley A, Wagner G, et al. The International Index of Erectile Function (IIEF) a multidimensional scale for assessment of erectile dysfunction. Urology 1997;49:822-830.

15. Herr H, Lee C, Chang S, Lerner S; Bladder Cancer Collaborative Group. Standardization of radical cystectomy and pelvic lymph node dissection for bladder cancer: A collaborative group report. J Urol 2004;171:1823-1828.

16. Skinner EC, Stein JP, Skinner DG. Surgical benchmarks for the treatment of invasive bladder cancer. Urol Oncol 2007; 25:66-71.

17. Collins JW, Hosseini A, Adding C, et al. Early recurrence patterns following totally intracorporeal robot-assisted radical cystectomy: Results from the EAU Robotic Urology Section (ERUS) scientific working group. Eur Urol 2017; 71:723-726.

18. Collins JW, Sooriakumaran P, Sanchez-Salas R, et al. Robot-assisted radical cystectomy with intracorporeal neobladder diversion: The Karolinska experience. Indian J Urol 2014;30:307-313.

19. Simone G, Tuderti G, Misuraca L, et al. Perioperative and mid-term oncologic outcomes of robotic assisted radical cystectomy with totally intracorporeal neobladder: Results of a propensity score matched comparison with open cohort from a single-centre series. Eur J Surg Oncol 2018;44:1432-1438.

20. Minervini A, Vanacore D, Vittori G, et al. Florence robotic intracorporeal neobladder (FloRIN): A new reconfiguration strategy developed following the IDEAL guidelines. BJU Int 2018;121:313-317.
21. Schwentner C, Sim A, Balbay MD, et al. Robot-assisted radical cystectomy and intracorporeal neobladder formation: On the way to a standardized procedure. World J Surg Oncol 2015;13:3.

22. Desai MM, Gill IS, de Castro Abreu AL, et al. Robotic intracorporeal orthotopic neobladder during radical cystectomy in 132 patients. J Urol 2014;192:1734-1740.

23. Atmaca AF, Canda AE, Gok B, Akbulut Z, Altinova S, Balbay MD. Open versus robotic radical cystectomy with intracorporeal Studer diversion. JSLS 2015;19:e2014.00193.

24. Desai MM, de Abreu AL, Goh AC, et al. Robotic intracorporeal urinary diversion: Technical details to improve time efficiency. J Endourol 2014;28:1320-1327.

25. Goh AC, Gill IS, Lee DJ, et al. Robotic intracorporeal orthotopic ileal neobladder: Replicating open surgical principle. Eur Urol 2012;62:891-901.

Address correspondence to: Abdullah Erdem Canda, MD

Department of Urology School of Medicine Koç University

Topkapi, Davupasa Cad., No. 4 Istanbul 34010

Turkey

E-mail: aecanda@ku.edu.tr

$\begin{aligned} & \quad \text { Abbreviations Used } \\ & \text { ASA }=\text { American Society of Anesthesiologists } \\ & \mathrm{BC}=\text { bladder cancer } \\ & \mathrm{BCG}=\text { bacillus Calmette-Guérin } \\ & \mathrm{BMI}=\text { body mass index } \\ & \mathrm{CSS}=\text { cancer-specific survival } \\ & \mathrm{CT}=\text { computed tomography } \\ & \mathrm{EBL}=\text { estimated blood loss } \\ & \mathrm{ED}=\text { erectile dysfunction } \\ & \mathrm{ePLND}=\text { extended pelvic lymph node dissection } \\ & \mathrm{ICSPF}=\text { intracorporeal Studer pouch formation } \\ & \mathrm{ICUD}=\text { intracorporeal urinary diversion } \\ & \mathrm{IIEF}=\text { International Index of Erectile Function } \\ & \mathrm{IRCC}=\text { International Robotic Cystectomy Consortium } \\ & \mathrm{LN}=\text { lymph node } \\ & \mathrm{LOS}=\text { length of hospital stay } \\ & \mathrm{NGT}=\text { nasogastric tube } \\ & \mathrm{NVB}=\text { neurovascular bundle } \\ & \mathrm{OS}=\text { overall survival } \\ & \mathrm{PCN}=\text { percutaneous nephrostomy } \\ & \mathrm{PDE}-5=\text { phosphodiesterase type } 5 \\ & \mathrm{pT}=\text { pathologic } \\ & \mathrm{RARC}=\text { robot-assisted radical cystectomy } \\ & \mathrm{RARP}=\text { robot-assisted radical prostatectomy } \\ & \mathrm{RC}=\text { radical cystectomy } \\ & \mathrm{RFS}=\text { recurrence-free survival rates } \\ & \mathrm{SD}=\text { standard deviation } \\ & \mathrm{SM}=\text { surgical margin } \\ & \mathrm{TURB}=\text { transurethral resection of bladder tumor } \\ & \mathrm{UI}=\text { urinary incontinence } \\ &\end{aligned}$

